\title{
Epidemiological and Cytopathological Profile of Dysplastic Lesions of the Cervix in South-Kivu/Dr Congo
}

\author{
Nyakio Olivier ${ }^{1,2,3}{ }^{*}$, Kibukila Fabrice ${ }^{4,5}$, Tambwe Albert ${ }^{3}$, Kakudji Prosper ${ }^{3}$, Kalenga Prosper ${ }^{3}$, \\ Kakoma Jean Baptiste ${ }^{3}$
}

\author{
${ }^{1}$ Department of Gynecology and Obstetrics, Faculty of Medecine, Evangelical University in Africa (EUA), \\ Bukavu, Democratic Republic of the Congo \\ ${ }^{2}$ Denis MUKWEGE Excellence Center, Bukavu, Democratic Republic of the Congo \\ ${ }^{3}$ Department of Gynecology-Obstetrics, Faculty of Medicine, University of Lubumbashi, \\ Lubumbashi, Democratic Republic of the Congo \\ ${ }^{4}$ Department of Surgery, Faculty of Medecine, Official University of Bukavu (UOB), Bukavu, Democratic Republic of the Congo \\ ${ }^{5}$ Department of Surgery, Faculty of Medecine, University of Burundi, Bujumbura, Burundi \\ Email: ^oliviernyakio@yahoo.fr, fabricekibukila92@gmail.com, albertmwembotambwe2008@yahoo.fr, \\ luhetekakudji@gmail.com, kalengamk@hotmail.com, jbszkakoma2016@gmail.com
}

How to cite this paper: Olivier, N., Fabrice, K., Albert, T., Prosper, K., Prosper, K. and Baptiste, K.J. (2021) Epidemiological and Cytopathological Profile of Dysplastic Lesions of the Cervix in South-Kivu/ Dr Congo. Open Journal of Obstetrics and Gynecology, 11, 162-182.

https://doi.org/10.4236/ojog.2021.112018

Received: January 20, 2021

Accepted: February 22, 2021

Published: February 25, 2021

Copyright (C) 2021 by author(s) and Scientific Research Publishing Inc. This work is licensed under the Creative Commons Attribution International License (CC BY 4.0).

http://creativecommons.org/licenses/by/4.0/

\begin{abstract}
Background: Cervical cancer is one of the most common cancers in women in the world. The recrudescence of dysplastic lesions is increasing, especially in developing countries, because of the absence of screening. The objective of this work is to determine the prevalence of dysplastic lesions of the cervix in women who are sexually active in South Kivu province. Methods: It was a cross-sectional, descriptive and analytical study of 625 women who came for gynecological consultation, all of whom had cervical-uterine Pap smears, during the period from January 1st, 2017 to December 31st, 2018 at Panzi General Referral Hospital (South Kivu, DR Congo). Data analysis was done using Epi Info software version 7. Results: The median age of the respondents was 34 years, $47.0 \%$ of them were married, and $59.0 \%$ had a low socio-economic level. The majority had first sexual intercourse between the ages of 15 and $20(67.5 \%)$, a number of former sexual partners estimated at 1 - 5 (87.8\%), did not use tobacco (97.4\%) and did not use contraception (78.1\%). Pap smear was normal in $82.88 \%$ of cases, inflammatory in $2.4 \%$ of cases and with cytologic abnormalities in $14.72 \%$ of cases. Rates of dysplastic lesions were significantly higher among women aged $\geq 35$ years $(\mathrm{p}=0.0245)$, brides $(\mathrm{p}=0.0183)$ and multiparous $(\mathrm{p}=0.0042)$. Multivariate analysis revealed the adjusted OR $(95 \%$ CI $)$ statistically insignificant $(\mathrm{p}<0.05)$ for the age group, marital status and parity respondents. Conclusion: Cervical can-
\end{abstract}


cer remains a real scourge in the world, especially in sub-Saharan Africa, where the diagnosis is often made when the pathology is at its stage almost incurable. Early detection of dysplastic lesions by Pap smear is therefore imperative in the eradication of this pathology.

\section{Keywords}

Dysplasic Lesions, Cervix, South Kivu, DRC

\section{Background}

Cervical cancer is one of the most common cancers in women worldwide [1] [2] [3]. In 2018, 569,847 cases were diagnosed with 311,000 deaths [4]. Women in low- and middle-income countries appear to be the most affected, compared with those in developed countries [1] [5] [6]. In addition, mortality from cervical cancer is expected to increase by $42 \%$ to 442,926 deaths in 2030 ; the largest increase will be in low-income and middle-income countries, where currently about $85 \%$ of cervical cancers and $87 \%$ of cervical cancer deaths occur [4].

Several factors contribute to this resurgence of cervical cancer in developing countries: lack of screening, early intercourse, multiple sexual partners, and STIs [1] [3] [5].

In Africa, the incidence of cervical cancer is increasing every year. The human papillomavirus, which is the causative agent of cervical cancer in $99 \%$ of cases, is the basis of $14.2 \%$ of cancers in sub-Saharan Africa, including cervical cancer [7]. The latter disproportionately affects this part of the African continent, where $9 \%$ of the world's female population over the age of 15 represents $14 \%$ of its incidence and $18 \%$ of its global mortality [7].

East Africa, like other parts of the continent, has incidence rates (42.7 per $100,000)$ and mortality $(27.6$ per 100,000$)$ of cervical cancer well above the incidence of cervical cancer. (14.0 out of 100,000) and global mortality (6.8 out of 100,000) [8]. However, in most countries in sub-Saharan Africa, epidemiological data on cervical cancer are not documented. Only 17\% of African countries have a national program and a specific budget to fight cervical cancer, and where the program exists, effective coverage may be low [9].

In the Democratic Republic of Congo, the health system is less organized and underfunded and many health facilities have been destroyed as a result of armed conflict, especially in the east of the country, where surviving hospitals are often poorly equipped and deprived of qualified medical personnel.

There is very little data on the prevalence of cervical dysplastic lesions in the DRC [9] [10] [11] [12]. This could be extrapolated from data collected in sub-Saharan Africa [12]. Thus, it is with the objective of having a more reliable reference, as regards the East of the DR Congo and more particularly the Province of South Kivu, that the present study was conducted. 


\section{Methods}

\subsection{Type and Population of Study}

This is a cross-sectional, descriptive and analytical study carried out in women who came to a gynecological consultation for cervical cancer screening during the period from January 1, 2017 to December 31, 2018 at the Panzi GRH (South Kivu, DR Congo). In total, we recorded 625 women, all of whom had Pap smears.

Pregnant women, those with a sexually transmitted disease other than HIV, those already receiving cervical cancer treatment and those who refused to respond to the questionnaire were excluded from the study.

\subsection{Collection of Data}

A pre-established form was completed by the clinical physician during the interview with the women who consented to the study, and gathered information on socio-demographic characteristics (age, marital status, occupation, level of education, socio-economic level, etc.), sexual and gynecological obstetrics (age at menarche, age at first sexual intercourse, number of previous sexual partners, type of sexual intercourse, age at first pregnancy, notion of sexual violence involving rape with penetration, notion of smoking, hormonal contraception, parity and HIV antecedent).

All the women included in the study benefited from cervical uterine smear sampling. This sampling was carried out after sensitization by a qualified medical staff and in respect of all ethical considerations. The cytopathological results made it possible to describe the different cytopathological aspects of cervical lesions.

\subsection{Variables}

The following variables were studied:

- Dependent variable:

It was represented by the cytopathological results. The cytopathological examination of the smear revealed the following aspects: normal and inflammatory smear, atypical lesions (ASC-US and AGC), low-grade squamous intraepithelial lesions (LSIL) and high-grade squamous intraepithelial lesions (HSIL). These results were grouped into two classes: atypical, low-grade and high-grade intraepithelial lesions (ASC-US + AGC + LSIL + HSIL) that are precancerous and those related to normal smear (normal + inflammatory smear; the latter being a lesion non-precancerous).

- Independent variables:

They were constituted by socio-demographic, sexual and gynecological characteristics of the women examined.

\subsection{Data Analysis}

Data analysis was done using Epi Info version 7 software. Descriptive statistics were used to describe women by sociodemographic, sexual and gynecological variables. The associations between the dependent variable and the set of expla- 
natory variables (in terms of proportions observed in the contingency tables) were tested using Pearson's Chi-2 test and Fisher's exact test for qualitative variables. Odds ratios (ORs) with a $95 \%$ confidence interval were used to measure the level of association between variables. For multivariate analysis, logistic regression was used to calculate adjusted ORs to identify possible determinants of dysplastic lesions. The materiality threshold was set at $\mathrm{p}<0.05$.

Ethical considerations were taken into account, as mentioned above, after favorable opinion of the local ethics committee and UNILU (University of Lubumbashi).

\section{Results}

\subsection{Characteristics of the Respondents}

Nearly half of the women surveyed were aged 35 and over (49.1\%), with a median age of 34 and married (47.0\%). The housewife accounted for $39.7 \%$ of the respondents, while $40.2 \%$ had a low socio-economic level (Table 1 ).

Table 1. Sociodemographic characteristics.

\begin{tabular}{|c|c|c|c|}
\hline Variable $(n=625)$ & Median (P25-P75) & $\mathbf{n}$ & (\%) \\
\hline \multicolumn{4}{|l|}{ Age } \\
\hline $15-24$ years & $34(23-46)$ & 175 & $(28.0)$ \\
\hline 25 - 34 years & & 143 & $(22.9)$ \\
\hline$\geq 35$ years & & 307 & $(49.1)$ \\
\hline \multicolumn{4}{|l|}{ Marital status } \\
\hline Single & & 155 & $(24.8)$ \\
\hline Married & & 294 & $(47.0)$ \\
\hline Others (widow, divorced, polygamy) & & 176 & $(28.2)$ \\
\hline \multicolumn{4}{|l|}{ Profession } \\
\hline Housewife & & 248 & $(39.7)$ \\
\hline farmer & & 139 & $(22.2)$ \\
\hline Others (civil servant, seller, ...) & & 238 & $(38.1)$ \\
\hline \multicolumn{4}{|l|}{ Level of education } \\
\hline Illiterate & & 163 & $(26.1)$ \\
\hline Primary & & 167 & $(26.7)$ \\
\hline Secondary & & 251 & $(40.2)$ \\
\hline Superior & & 44 & $(7.0)$ \\
\hline \multicolumn{4}{|l|}{ Socio-economic level } \\
\hline Low & & 369 & $(59.0)$ \\
\hline Way & & 256 & $(410)$ \\
\hline
\end{tabular}


Just over half of the women had menarche between 14 and 15 years of age $(51.8 \%)$, with an average age of $13.9 \pm 1.6$ years. The majority of them had their first sexual intercourse between the ages of 15 and 20 (67.5\%), and a number of former sexual partners estimated at $1-5(87.8 \%)$. Normal sex was the most common type (94.7\%). The age at first pregnancy was in most cases between 15 and 20 years (68.8\%). The majority of women did not experience sexual violence (73.9\%), did not use tobacco (97.4\%) and did not use contraception (78.1\%). Several of them (59.0\%) were multiparous. Those who reported an antecedent of HIV accounted for $21.9 \%$ (Table 2).

\subsection{Cytopathological Aspects Observed in the Respondents}

For all the respondents (Table 3), the cervical uterine smear was normal in $82.88 \%$ and inflammatory in $2.4 \%$ of the cases, whereas the cytological abnormalities, which were found in $14.72 \%$ of the cases, included $9.44 \%$ of atypia (8.8\% of ASC-US, $0.48 \%$ of AUC-H and $0.16 \%$ of AGC), $4.48 \%$ low-grade squamous intraepithelial lesions (LSIL) and $0.8 \%$ high-grade squamous intraepithelial lesions (HSIL).

\section{- Cytopathological results in the respondents.}

Thus, out of a total of 625 women examined, 92 or $14.7 \%$ (95\% CI: $12.1 \%$ $17.8 \%$ ) had dysplastic lesions (ASC-US, ASC-H, LSIL, HSIL and AGC) against $85.3 \%$ with normal and inflammatory smear.

\subsection{Sociodemographic Characteristics and Cytological Aspects}

The rate of dysplastic lesions was significantly higher among women in the age group $\geq 35$ years, the risk being doubled compared to their counterparts aged 25 - 34 (OR 95\% CI: 2.1 [1, 10 - 4.24], $\mathrm{p}=0.0245$ ). The difference was also significant $(\mathrm{p}=0.0183)$ for brides and other marital statuses (widowed, divorced, polygamous) compared to single women, with the risk of having a dysplastic lesion being multiplied by about two, respectively (OR 95\% CI: 1.97 [1.003 - 4.12]) and three (95\% OR: $2.61[1.28-5.62])$. On the other hand, there was no significant difference $(\mathrm{p}<0.05)$ in women's occupation, education level and socio-economic level (Table 4).

\subsection{Sexual, Gyneco-Obstetric and Cytological Characteristics}

The rate of dysplastic lesions was very significantly higher in nulliparas and in primiparous and pauciparous patients, the risk being respectively nearly five and three times higher compared to multiparas (OR 95\% CI: 4.73 [1.69 - 18.36] and 3.33 [1.08 - 13.75], $\mathrm{p}<0.0042)$. In contrast, there was no significant difference in dysplastic lesions between menarche age groups $(p=0.9794)$, age groups at first intercourse $(p=0.8144)$. ), number of previous sexual partners $(p=0.4448)$, type of sexual intercourse $(p=0.4496)$, age at first pregnancy $(p=0.7535)$, notion of sexual abuse $(p=0.3552)$, smoking concept $(p=0.5734)$, hormonal contraception $(\mathrm{p}=0.1181)$ and HIV antecedent $(\mathrm{p}=0.158)$ among respondents (Table 5). 
Table 2. Sexual and gynecological obstetrical characteristics.

\begin{tabular}{|c|c|c|c|}
\hline Variable $(n=625)$ & Mean (standard deviation) & $\mathbf{n}$ & (\%) \\
\hline Age at menarche & $13.9(1.6)$ & & \\
\hline$\leq 13$ years & & 259 & $(41.4)$ \\
\hline $14-15$ years & & 324 & $(51.8)$ \\
\hline$\geq 16$ years & & 42 & $(6.7)$ \\
\hline \multicolumn{4}{|l|}{ Age at first intercourse } \\
\hline$<15$ years & & 140 & $(22.4)$ \\
\hline $15-20$ years & & 422 & $(67.5)$ \\
\hline$>20$ years & & 63 & $(10.1)$ \\
\hline \multicolumn{4}{|c|}{ Number of prevous sexual partners } \\
\hline $1-5$ & & 549 & $(87.8)$ \\
\hline$\geq 6$ & & 76 & $(12.2)$ \\
\hline \multicolumn{4}{|c|}{ Type of sexual intercourse } \\
\hline Normal & & 592 & $(94.7)$ \\
\hline Other & & 33 & (5.3) \\
\hline \multicolumn{4}{|c|}{ Age at first pregnancy $(n=552)$} \\
\hline$<15$ years & & 61 & $(11.1)$ \\
\hline $15-20$ years & & 380 & $(68.8)$ \\
\hline$>20$ years & & 111 & $(20.1)$ \\
\hline \multicolumn{4}{|l|}{ Sexual violence } \\
\hline Yes & & 163 & $(26.1)$ \\
\hline No & & 462 & $(73.9)$ \\
\hline \multicolumn{4}{|l|}{ Tobacco } \\
\hline Yes & & 16 & $(2.6)$ \\
\hline No & & 609 & $(97.4)$ \\
\hline \multicolumn{4}{|l|}{ Hormonal contraception } \\
\hline Yes & & 137 & $(21.9)$ \\
\hline No & & 488 & $(78.1)$ \\
\hline \multicolumn{4}{|l|}{ Parity } \\
\hline Nulliparous & & 91 & (14.6) \\
\hline Primo-paucipares & & 165 & $(26.4)$ \\
\hline Multiparous & & 369 & $(59.0)$ \\
\hline \multicolumn{4}{|l|}{ HIV antecedent } \\
\hline Yes & & 137 & $(21.9)$ \\
\hline No & & 488 & $(78.1)$ \\
\hline
\end{tabular}


Table 3. Cytopathological aspects observed in the respondents.

\begin{tabular}{ccc}
\hline Cytopathological results & Frequency & $\%$ \\
\hline Normal smear & 518 & 82.88 \\
Inflammatory & 15 & 2.4 \\
ASC-US & 55 & 8.8 \\
ASC-H & 3 & 0.48 \\
LSIL & 28 & 4.48 \\
HSIL & 5 & 0.8 \\
AGC & 1 & 0.16 \\
Total & 625 & 100
\end{tabular}

Table 4. Sociodemographic characteristics and cytological aspects.

\begin{tabular}{|c|c|c|c|c|c|}
\hline Variables & $\mathrm{n}$ & $\begin{array}{l}\text { Dysplastic } \\
\text { lesions \% }\end{array}$ & $\begin{array}{c}\text { Gross OR } \\
\text { (CI 95\%) }\end{array}$ & $\mathrm{Khi}^{2}$ (ddl) & $\mathbf{P}$ \\
\hline \multicolumn{6}{|l|}{ Age } \\
\hline $15-24$ years & 21 & 12.0 & $1.25[0.58-2.78]$ & $7.4187(2)$ & 0.0245 \\
\hline $25-34$ years & 14 & 9.8 & 1 & & \\
\hline$\geq 35$ years & 57 & 18.6 & $2.1[1.10-4.24]$ & & \\
\hline \multicolumn{6}{|l|}{ Marital status } \\
\hline Single & 13 & 8.4 & 1 & $7.9968(2)$ & 0.0183 \\
\hline Married & 45 & 15.3 & $1.97[1.003-4.12]$ & & \\
\hline Others (widow, divorced, polygamy) & 34 & 19.3 & $2.61[1.28-5.62]$ & & \\
\hline \multicolumn{6}{|l|}{ Profession } \\
\hline Housewife & 36 & 14.5 & $1.05[0.61-1.82]$ & $0.5161(2)$ & 0.7725 \\
\hline farmer & 23 & 16.5 & $1.23[0.65-2.28]$ & & \\
\hline Others (civil servant, seller...) & 33 & 13.9 & 1 & & \\
\hline \multicolumn{6}{|l|}{ Level of education } \\
\hline Illiterate & 24 & 14.7 & $1.10[0.59-2.01]$ & $0.7916(3)$ & 0.8515 \\
\hline Primary & 26 & 15.6 & $1.17[0.65-2.12]$ & & \\
\hline Secondary & 34 & 13.5 & 1 & & \\
\hline Superior & 8 & 18.2 & $1.41[0.52-3.45]$ & & \\
\hline \multicolumn{6}{|l|}{ Socio-economic level } \\
\hline Low & 57 & 15.4 & $1.15[0.71-1.87]$ & $0.2512(1)$ & 0.3095 \\
\hline Way & 35 & 13.7 & 1 & & \\
\hline
\end{tabular}


Table 5. Sexual, gyneco-obstetric and cytological characteristics.

\begin{tabular}{cccccc}
\hline Variable & $\mathbf{n}$ & $\begin{array}{c}\text { Dysplastic } \\
\text { lesions }\end{array}$ & $\begin{array}{c}\text { Gross OR } \\
(\mathrm{CI} 95 \%)\end{array}$ & $\mathrm{Khi}^{2}(\mathrm{ddl})$ & $\mathbf{P}$ \\
\hline $\begin{array}{c}\text { Age at menarche } \\
\quad 13 \text { years }\end{array}$ & 39 & 15.1 & $\mathbf{1 . 0 6 [ 0 . 4 1 - 3 . 2 9 ]}$ & $\mathbf{0 . 0 4 1 7}(2)$ & 0.9794 \\
$14-15$ years & 47 & 14.5 & $1.02[0.39-3.12]$ & \\
$\geq 16$ years & 6 & 14.3 & 1
\end{tabular}

Age at first intercourse

$\begin{array}{cccc}<15 \text { years } & 16 & 11.4 & 1 \\ 15-20 \text { years } & 66 & 15.6 & 1.43[0.78-2.76] \\ >20 \text { years } & 10 & 15.9 & 1.46[0.55-3.68]\end{array}$

Number of prevous sexual partners

$\begin{array}{cccccc}1-5 & 12 & 15.8 & 1.09[0.51-2.17] & 0.0117(1) & 0.4448 \\ \geq 6 & 80 & 14.6 & 1 & & \end{array}$

Type of sexual intercourse

$\begin{array}{cccccc}\text { Normal } & 88 & 14.9 & 1.26[0.42-5.07] & 0.0326(1) & 0.4496 \\ \text { Other } & 4 & 12.1 & 1 & & \end{array}$

Age at first pregnancy

$\begin{array}{cccc}<15 \text { years old } & 9 & 14.8 & 1 \\ 15-20 \text { years } & 60 & 15.8 & 1.08[0.49-2.63] \\ >20 \text { years } & 20 & 18.0 & 1.27[0.51-3.41]\end{array}$

\section{SexualViolence}

\begin{tabular}{|c|c|c|c|c|}
\hline Yes & 22 & 13.5 & 1 & $0.1475(1)$ \\
\hline No & 70 & 15.2 & $1.14[0.67-2.02]$ & \\
\hline
\end{tabular}

Tobacco

$\begin{array}{cccccc}\text { Yes } & 2 & 12.5 & 1 & 0.0107(1) & 0.5734 \\ \text { No } & 90 & 14.8 & 1.21[0.27-11.18] & & \end{array}$

Hormonal contraception

\begin{tabular}{cccccc} 
Yes & 22 & 18.6 & $1.43[0.80-2.47]$ & $1.7843(1)$ & 0.1181 \\
No & 70 & 13.8 & 1 & & \\
Parity & & & & & \\
Multiparous & 66 & 17.9 & $4.73[1.69-18.36]$ & $10.9266(2)$ & 0.0042 \\
Primo-paucipares & 22 & 13.3 & $3.33[1.08-13.75]$ & & \\
Nulliparous & 4 & 4.4 & 1 & & \\
HIV antecedent & & & & & \\
Yes & 16 & 11.7 & 1 & $1.0011(1)$ & 0.1584 \\
No & 76 & 15.6 & $1.39[0.77-2.66]$ & & \\
\hline
\end{tabular}




\subsection{Results of Multivariate Analysis}

To measure accurately the linkage power between factors associated with dysplastic lesions, a multivariate analysis (logistic regression) was performed as advertised in the methodology and took into account significant independent variables following the bivariate analysis of dysplastic lesions cases observed in the respondents (Table 4 and Table 5).

Multivariate analysis revealed statistically insignificant ORs $(p<0.05)$ for the age, marital status and parity variables of the respondents (Table 6).

\section{Discussion}

\subsection{Sociodemographic Characteristics}

\subsubsection{Age}

Almost half of the women were aged 35 and over (49.1\%) with a median age of 34 , the modal class being the 15 - 24 age group.

Our observations are similar to those of Massad S et al. [13] in the United States (median age 34 years) and Blumenthal PD et al. [14] in Ghana (34.0 years). A similar study was carried out by Söderlund S et al. [15] who found in Sweden a median age of 43.5 years whereas Catarino $\mathrm{R}$ et al. [16] in Cameroon and Yessaian A et al. [17] in the United States had a median age of 39 years and 42 years respectively. Many other authors have made similar studies; Benoy HI et al. in Belgium [18] and Lorin L et al. [19] in France reported a median age greater than ours (45 and 52 respectively), whereas Hernadi $\mathrm{Z}$ et al. [20] in Hungary had a median age slightly lower than ours (32 years).

Thus, the occurrence of dysplastic lesions of the cervix in a relatively mature age could be explained in our environment by the precocity of sexual intercourse and the multiplicity of sexual partners, consequences of a precarious socio-economic level $(59.0 \%$ of women with a low socio-economic level compared to $41.0 \%$ with a way socio-economic level).

\subsubsection{Marital Status}

In our series, $47.0 \%$ of women were married and $24.8 \%$ were single. Fatouma B. [21] found in Mali a much higher rate than ours of married women (90\%); Catarino $\mathrm{R}$ et al. [16] reported a rate of $58.2 \%$ of married women versus $33.8 \%$ of single, almost the same rate as Gordon JR et al. [22] (56.0\% of married women) and moderately higher than Shin SS et al. [23] (48.2\% of married women) in their respective studies in India, but much higher than that of Mitchell SM et al. [24] in sub-Saharan Africa (10.55\% of married women).

Table 6. OR adjusted (95\% CI) factors associated with dysplastic lesions.

\begin{tabular}{|c|c|c|c|}
\hline Variables & $n=625$ & Adjusted OR (CI 95\%) & P-value \\
\hline Age (Age groups) & & $0.59[0.03-11.14]$ & 0.7251 \\
\hline Marital status & & $1.94[0.11-33.18]$ & 0.646 \\
\hline Parity & & $1.40[0.06-33.65]$ & 0.834 \\
\hline
\end{tabular}


Several other studies have been done and have shown the predominance of married women in case of dysplastic lesions of the cervix [25]-[30].

This rate, close to half of the married women in our study, is linked to the increase in early weddings, which is becoming increasingly important, especially in rural areas, the main bastions of the majority of our patients.

\subsubsection{Profession}

Housewives accounted for $39.7 \%$ of the cases in our series. On the other hand, Fatouma B [21] found in Mali $62.2 \%$ of housewives compared to 52\% for Konate S [31] a year earlier and $31.7 \%$ for Catarino R. in Cameroon [16]. Liang X et al. [30] reported in their study in China, a rate of $42.4 \%$ of housewives in their series.

The slightly high rate of housewives in our series is explained not only by the low level of economic life that compels the woman to adopt a wait-and-see attitude and to settle for the little that the husband can bring, but also by the social cultural constraint of the region, where it is estimated that the woman, regardless of her grade or the value of her degree, is dedicated to the care of the house.

\subsubsection{Level of Education}

In our study, $7.0 \%$ of women had a higher level of education, $40.2 \%$ had gone to high school while $26.7 \%$ had a primary level of education and $26.1 \%$ were illiterates.

Wright TC et al. [32] found in Athens a rate, higher than that of our series, of $25.4 \%$ of women who attended higher education. Mitchell SM et al. [24] reported in their series in sub-Saharan Africa a rate, lower than ours, of $19.09 \%$ of women with a high school education. Arora $\mathrm{R}$ et al. [33] found $45 \%$ of illiterates in India, which is higher than that of our series, while Gordon JR et al. [22] observed, still in India, several years later a rate of $8 \%$ illiterate, which is far inferior to ours. Husaiyin S et al. [25] reported in China a rate, higher than ours, of $68.0 \%$ of women with no more than primary education, while Tapera $\mathrm{O}$ et al. [26] found a higher rate in Zimbabwe than women in our series, of women with a high school education (71\%).

The very low rate of women who attended higher education in our region would not only be a consequence of a precarious socio-economic level, but also and especially of the negativist conception of the culture of the environment where some people think that only men should legitimately have access to higher education, while women have to be content with secondary education.

\subsection{Sexual and Gyneco-Obstetrical Characteristics}

\subsubsection{Age at First Intercourse}

Early age at first intercourse is one of the risk factors for the occurrence of dysplastic lesions of the cervix theoretically documented by almost all authors. There are many studies that have been conducted on this subject. Catarino $\mathrm{R}$ et al. [16] reported in their series in Cameroon that $69.4 \%$ of women had their first sexual intercourse before the age of 19. For Arora et al. [33], this rate was 50.6\% 
of women who had had their first sexual intercourse before the age of 19. As for Shin SS et al. [23], they reported in India a rate of $51.4 \%$ of women who had their first sexual intercourse before the age of 17 years.

Several other studies have shown that the majority of women with dysplastic lesions of the cervix have had their first sexual intercourse at an early age [34] [35] [36] [37]. In our series, $67.5 \%$ of women had their first sexual intercourse between the ages of 15 and 20 years. This early age at first intercourse is an immediate consequence of the country's socio-economic level, which is one of the lowest in Africa.

\subsubsection{Number of Sexual Partners}

The multiplicity of sexual partners is, along with the early age at first intercourse, a risk factor for the occurrence of cervical dysplastic lesions.

In our series, the number of sexual partners did not exceed five (87\%). Several authors made similar studies and came up with the following results: Catarino $\mathrm{R}$ et al. [16] found in their study in Cameroon that the number of sexual partners was largely between 2 and 5 (45.4\%); Shin SS et al. [23] also reported in India a rate of $77.3 \%$ of women with a number of sexual partners between 2 and 5; Jolly PE et al. [34], meanwhile, obtained in their study in Swaziland a rate of $88.6 \%$ of women with more than one sexual partner; Wudtisan J et al. [35] in Thailand and Hooi DJ et al. [37] in the Netherlands, for their part, had rates of $66.7 \%$ and $69.9 \%$ of women with a number of at least two sexual partners in their respective studies.

Thus, the precarious financial system of the country, at the base of a dismal socio-economic level of the population, would explain this recourse of women to multiple sexual partners, hoping thus to cover their needs.

\subsubsection{Type of Sexual Intercourse}

Normal sex was the most common type (94.7\%) in our work. Other authors have noted the same observations in their work [34]. This recourse to normal sexual intercourse in our environment are the results of the great conservation of morals emanating from African culture, for which intercourse can only be performed vaginally, while others constitute a prohibition.

\subsubsection{Sexual Violence}

In our work, 163 women, or $26.1 \%$ of the total, had been victims of sexual violence. Several similar studies have been conducted that have found a correlation between cervical cancer and sexual violence [38] [39] [40] [41].

This no insignificant rate of women victims of sexual violence $(26.1 \%)$ in our series is the exact reflection of the everyday life of the Congolese in the east of the country, the latter being the real theater of decades of wars perpetrated by different armed groups.

\subsubsection{Hormonal Contraception}

Taking hormonal contraception in women with oncogenic human papillomavi- 
rus increases the risk of progression to cancer by a factor of four [1]. In our study, only $21.9 \%$ of women had used hormonal contraception.

Catarino R et al. [16] found in their study in Cameroon a lower rate than ours for women who used hormonal contraception (13.9\%), while Arora R et al. [33] reported in India a higher rate than ours of $43.37 \%$ of women who used this type of contraception.

Indeed, the results of the studies on this subject are divergent according to the environment. This is how Godfrey M.A.L et al. [42] in their study in the United Kingdom, reported a high rate of $50.0 \%$ of women who used oral contraception, compared to $30 \%$ observed by Wudtisan J et al. [35] in Thailand and $11.2 \%$ reported by Thay S et al. [29] in Cambodia. Many other studies have also reported a significant percentage of women who used hormonal contraception in the past before developing dysplastic lesions of the cervix [43] [44]. The low rate (21.9\%) of women using oral contraception in our environment is the result of the low inclination of women for this practice, for fear of the side effects of contraception, often dramatically exaggerated by the non-caregivers, for lack of information from the majority of the medical profession.

\subsubsection{Parity}

Most cases of dysplastic lesions of the cervix of our series were multiparous (59\%). Arora R et al. [33] also reported in India a rate of $61.12 \%$ of multiparous women in their study of cervical dysplastic lesions, compared to $40.8 \%$ for Lorin L et al. [19] in France and 15.2\% for Thay S et al. [29] in Cambodia. Godfrey M.A.L et al. [42] found a significant proportion of $64.5 \%$ of multiparous women in the United Kingdom.

Overall, the majority of authors reported a considerable rate of multiparous women in their studies of dysplastic lesions of the cervix [45], which is in the same order as the results of our series.

\subsection{HIV Antecedent}

The immunosuppression (HIV infection, immunosuppressive therapy, etc.) plays a major role in the occurrence of dysplastic lesions of the cervix [1] [46]. Several studies have supported the coexistence between HIV infection and human papillomavirus [34] [47] [48] [49] [50].

In our series, about a quarter of women, or $21.9 \%$, was HIV positive. This non-insignificant frequency of HIV infection is explained by the low standard of living of the population, pushing girls and women into unsafe sexual practices and unprotected sex.

\subsection{Smoking History}

Smoking is one of the risk factors for cervical cancer [1] [46]. Our study reveals a low rate of women consuming tobacco (2.5\%). Shin SS et al. [23] had a slightly lower rate than ours of $1.8 \%$ of women who had used tobacco in the past.

Other authors had far greater results than ours regarding women who had 
used tobacco in the past: Godfrey M.A.L et al. [42] in the United Kingdom (41.9\%), Pokomandy A et al. [51] in Canada (54.1\%); Agorastos A et al. [52] in Greece (77.45\%), Wudtisan J et al. [35] in Thailand (26.7\%) and Bogani G et al. [53] in Italy (20.9\%).

This very low rate of women consuming tobacco in our environment is explained by the absence of this habit in the community, as smoking is considered to be the preserve of men.

\subsection{Cytopathological Aspects}

Pap smear is the screening tool currently recommended for precancerous and cancerous cervix lesions. The technique developed by Papanicolau and Babès is inexpensive, simple and acceptable, painless and reproducible, non-invasive, with no contraindications [46]. For more than half a century, it has been effective since its introduction, the invasive carcinoma of the cervix has seen its frequency considerably decreased. However, the biopsy remains the gold standard, it is she who confirms the lesions after detection by cytology and orientation by colposcopy [46]. Biopsy is therefore indicated in cytological lesions of low and high grade [46].

In our series, cervical-uterine pap smears was normal in $82.88 \%$ and inflammatory in $2.4 \%$ of cases, while cytological abnormalities, which were found in 14.7\% of cases, included: $9.44 \%$ atypia (8.8\% ASC-US, $0.4 \%$ ASC-H and $0.16 \%$ AGC); $4.48 \%$ low-grade squamous intraepithelial lesions (LSIL) and $0.8 \%$ high-grade squamous intraepithelial lesions (HSIL). Wang JJ et al. [54] in China found: normal cervical-uterine pap smears in $71.7 \%$ of cases versus $14.8 \%$ ASCUS; $8.7 \%$ of LSIL and 2.3\% of HSIL. Kasap B et al. [55] found in their study in Turkey: a rate of $84.9 \%$ normal cervical-uterine pap smears; $1.55 \%$ ASC-US; 5.3\% LSIL and 4.0\% HSIL. Garbuglia AR et al. [50] in Italy had the following results: normal cervical-uterine pap smears in $76.4 \%$ of cases; ASC-US, LSIL and HSIL in $24.4 \%$ of cases while Correa CM et al. [56] obtained a normal cervical-uterine pap smear in $63.2 \%$ in Brazil. Agaba AP et al. [57] reported, in Nigeria, 31.7\% of normal cervical-uterine pap smears; 39.3\% ASC-US; $15.2 \%$ of LSIL and $13.8 \%$ of HSIL. Takamatsu R et al. [58] in Laos resulted in the following results: $90.7 \%$ normal cervical-uterine pap smears; $5.3 \%$ ASC-US; 0.6\% ASC-H; $2.3 \%$ of LSIL; $0.9 \%$ HSIL and $0.07 \%$ SCC.

In view of the results of the above studies, we can say that cervical cytopathology was normal in the majority of cases in our series. This normality of the cervical-uterine pap smears is explained by the sensitivity of this examination which is about $70 \%$ to $80 \%$.

\subsection{Sociodemographic Characteristics and Cytology}

The study of the association between socio-demographic characteristics and cytology (Table 4) shows that the proportion of dysplastic lesions was significantly higher in women $\geq 35$ years of age (18.6\%), more particularly compared to the 
25 - 34 age group (9.8\%) with almost twice the risk of having dysplastic lesions $(\mathrm{p}<0.0245, \mathrm{OR}=2.1,95 \% \mathrm{CI}[1.10-4.24])$. With regard to marital status, brides (15.3\%) and widows, divorced and women in polygamous unions (19.3\%), compared with single men (8.4\%), had a significantly higher ( $\mathrm{p}=$ 0.0183 ) dysplastic lesions of the cervix with respectively two and three times more risk of developing this type of lesions ( $\mathrm{OR}=1.97,95 \%$ CI [1.003 - 4.12] and $\mathrm{OR}=2.61,95 \% \mathrm{CI}[1.28-5.62])$.

On the other hand, we did not note a statistically significant difference according to the occupation, the level of education and the socio-economic level, notwithstanding the risk more or less high to present dysplastic lesions highlighted in the women farmers (OR $=1.23,95 \%$ CI $[0.65-2.28], \mathrm{p}=0.7725)$, women with a higher level of education $(\mathrm{OR}=1.41,95 \%$ CI $[0.52-3.45], \mathrm{p}=$ 0.8515 ) and women of low socioeconomic status (OR $=1.15,95 \%$ CI $[0.71$ 1.87], $\mathrm{p}=0.3095)$.

Several studies have been done and have revealed the correlation between socio-demographic characteristics and cytopathology in case of precancerous lesions of the cervix.

Indeed, Adenis A et al. [59] found in their study in Guyana a higher risk of developing dysplastic lesions in women aged 50 to 64 than in all women $(\mathrm{OR}=$ $4.8,95 \%$ CI [0.6\%] 39.5]); it was the same for those with a low level of education $(\mathrm{OR}=2.1,95 \% \mathrm{CI}[0.5-8.9])$ without the difference being significant. Berraho $\mathrm{M}$ et al. [60] have observed in their series in Morocco a high risk of cervical cancer in divorced women (OR vs. married women $=2.4,95 \%$ CI $[1.3-4.6]$ ), women with (95\% CI 95\%), women living in rural areas (OR $=10.7,95 \%$ CI [5.3 - 21.8]) and those with a low socio-economic level (OR $=3.1,95 \%$ CI [1.8 - 5.4]).

Vinodhini K et al. [61] found in their study in India that the proportion of dysplastic lesions was statistically higher among illiterate women $(\mathrm{OR}=8.28$, 95\% CI [5.51 - 12.83], $\mathrm{p}<0.004)$.

We find that the results are slightly different according to the authors, this would be related to the sample size of each study, a key element for statistical significance.

\subsection{Sexual, Gyneco-Obstetrical and Cytology Characteristics}

The proportion of dysplastic lesions in our series was very significantly ( $\mathrm{p}=$ $0.0042)$ higher in multiparous (17.9\%) and primiparous-pauciparas (13.3\%) than in nulliparous (4.4\%), the risk being multiplied by nearly five (OR $=4.73,95 \%$ CI [1.69 - 18.36]) and three (OR = 3.33, 95\% CI [1.08 - 13.75]).

In contrast, we did not find a statistically significant difference in the proportion of dysplastic lesions: between age groups at menarche $(\mathrm{p}=0.9794)$; between age groups at first intercourse $(\mathrm{p}=0.8144$, the risk being slightly higher among women who had their first sexual intercourse beyond 20 years $(\mathrm{OR}=1.46,95 \%$ CI $[0.55-3.68])$, based on the number of previous sexual partners $(\mathrm{p}=0.4448)$ and the type of intercourse $(p=0.4496)$, with the risk being slightly higher 
among women reporting normal sexual intercourse $(\mathrm{OR}=1.26$ 95\% CI 0.42 $5.07)$, depending on the age at first pregnancy $(\mathrm{p}=0.7535)$, the risk being slightly higher for women who had first pregnancy beyond 20 years $(\mathrm{OR}=1.27$, $95 \%$ CI $[0.51-3.41])$, compared to the notion of sexual violence $(\mathrm{p}=0.3552)$, smoking ( $\mathrm{p}=0.5734)$ and hormonal contraception $(\mathrm{p}=0.1118)$, with a slightly higher risk for women who used hormonal contraception $(\mathrm{OR}=1.43,95 \% \mathrm{CI}$ [0.80 - 2.47]) as well as according to the antecedent HIV infection ( $\mathrm{p}=0.1584)$.

Berraho $\mathrm{M}$ et al. [60] reported from their study in Morocco: a higher risk of developing cervical dysplastic lesions in women who had menarche between 13 and 14 years than those who had menarche at 15 years and beyond $(\mathrm{OR}=3.6$, 95\% CI [2.1 - 6.2] and OR = 2.4, 95\% CI [1.3 - 4.4], respectively); and a higher risk in multiparous women starting from third parity and beyond $(\mathrm{OR}=1.4$, $95 \%$ CI [1.2 - 3.9]), in women practicing oral contraception (OR $=1.8,95 \% \mathrm{CI}$ $[1.2-2.8])$ and those with normal sexual intercourse $(\mathrm{OR}=3.3,95 \%$ CI $[1.8$ 6.4]).

Adenis A et al. [59] had the following results in Guyana: a higher risk but no significant difference in large multiparas (OR $=2.1,95 \%$ CI [0.5 - 11.2]), women with age at first intercourse $\geq 18$ years $(\mathrm{OR}=1.5,95 \% \mathrm{CI}[0.4-6.0])$ and with only one sexual partner $(\mathrm{OR}=8.2,95 \% \mathrm{CI} 0.8-84.5)$ as well as a higher risk with a significant difference in women taking non-oral contraception $(\mathrm{OR}=3.3$, 95\% CI [1.1 - 10.4]).

As for Vidal AC et al. [62], they had noted in Tanzania a higher proportion of dysplastic lesions with a statistically significantly greater difference in oral contraceptives $(\mathrm{p}<0.003)$ and HIV infection $(\mathrm{p}<0.0001)$. However, the difference was not statistically significant in terms of number of sexual partners $(p<0.4)$, marital status $(\mathrm{p}<0.6)$, and smoking status $(\mathrm{p}<0.6)$.

Vinodhini $\mathrm{K}$ et al. [61] found in their study in India that the proportion of dysplastic lesions was higher, with a statistically significant difference, among women who had their first sexual intercourse at age 15 and below $(\mathrm{OR}=4.21$; $95 \%$ [3.82 - 8.82], $\mathrm{p}<0.04$ ), in case of menarche between the age of 13 and 14 years $(\mathrm{OR}=4.19,95 \% \mathrm{CI}[2.87-6.11 \mathrm{P}<0.04)$, in multiparous women with a delivery number $\geq 3(\mathrm{OR}=19.2,95 \%$ CI $[10.78-34.44], \mathrm{p}<0.001)$ and in women with at least three intercourse per week (OR $=6.70,95 \%$ CI [4.41 10.16 ], $\mathrm{p}<0.01)$. On the other hand, they did not note any significant statistical difference with respect to socioeconomic level $(\mathrm{p}<0.44)$, marital status ( $\mathrm{p}<$ $0.12)$ and number of sexual partners $(\mathrm{p}<0.45)$.

Ali-Risasi C et al. [9], after their study in the city of Kinshasa, the following results with respect to HIV infection: the risk of developing low grade dysplastic lesions (LSIL) was higher among HIV-negative widows compared to HIV-positive widows compared to same-status spouses ( $\mathrm{OR}=8.33$, 95\% CI [0.41 - 170.67] and $\mathrm{OR}=1.16,95 \% \mathrm{CI}[0.45-2.94])$, seronegative multiparas than seropositive $(\mathrm{OR}=10.01,95 \% \mathrm{CI}[1.18-75.36]$ and $\mathrm{OR}=1.31,95 \% \mathrm{CI}[0.49-3.51])$ in comparison with women with gestations $\leq 2$ sharing the same serological status. 
Also in their study, multivariate analysis revealed a slightly elevated risk for HIV-positive women who had aborted in the past (risk increased by about two-fold) compared to women with gestationality $\leq 2$ sharing the same serologic status $(\mathrm{OR}=1.98,95 \% \mathrm{CI}[0.83-4.75])$. It also noted a significantly higher risk for HIV-negative single $(\mathrm{OR}=5.26,95 \% \mathrm{CI}[0.27-102.32])$ and seronegative widows $(\mathrm{OR}=4.34,95 \% \mathrm{CI}[0.18-105.99])$ compared to brides with the same serological status.

Thus, several studies have been conducted on the correlation between cytopathology and the sexual or behavioral and gynecological characteristics of women, but the results are slightly different. It has to be said that in the majority of studies the same theoretically documented risk factors predisposing to the development of dysplastic lesions of the cervix are incriminated, even if, according to the studies, the rib ratios look slightly different with various statistics meanings.

\section{Conclusion}

Cervical cancer remains a real scourge in the world, especially in sub-Saharan Africa, where the diagnosis is often made when the pathology is at its stage almost incurable. Early detection of dysplastic lesions by Pap smear is therefore imperative in the eradication of this pathology.

\section{Acknowledgements}

We thank all those who contributed to the realization of this work, and more particularly to our Master, Professor Jean Baptiste KAKOMA

\section{Competing Interests}

We declare, unanimously, that there is no conflict of interest between the authors.

\section{References}

[1] Lansac, J. (2014) Gynécologie pour le praticien. Elsevier Masson, Paris, 81-107.

[2] Castle, P.E. and Giuliano, A.R. (2003) Genital Tract Infections, Cervical Inflammation, and Antioxidant Nutrients-Assessing Their Roles as Human Papillomavirus Cofactors. Journal of the National Cancer Institute Monographs, 7234, 29-34. https://doi.org/10.1093/oxfordjournals.jncimonographs.a003478

[3] OMS: Centre International de Recherche sur le Cancer (2018) Dernières données mondiales sur le cancer: Le fardeau du cancer atteint 18.1 millions de nouveaux cas et 9.6 millions de décès par cancer en 2018. 8-10.

[4] Rahman, R., Clark, M.D., Collins, Z., Traore, F., Dioukhane, E.M., Thiam, H., et al. (2019) Cervical Cancer Screening Decentralized Policy Adaptation: An African Rural-Context-Specific Systematic Literature Review. Global Health Action, 12, Article ID: 1587894. https://doi.org/10.1080/16549716.2019.1587894

[5] OMS (2017) La lutte contre le cancer du col de l'utérus; Guide des pratiques essentielles, 2ème édition. 
[6] Kasa, A.S., Tesfaye, T.D. and Temesgen, W.A. (2018) Knowledge, Attitude and Practice towards Cervical Cancer among Women in Finote Selam City Administration, West Gojjam Zone, Amhara Region, North West Ethiopia, 2017. African Health Sciences, 18, 623-636. https://doi.org/10.4314/ahs.v18i3.20

[7] Klein, C., Gonzalez, D., Samwel, K., Kahesa, C., Mwaiselage, J., Aluthge, N., et al. (2019) Relationship between the Cervical Microbiome, HIV Status, and Precancerous Lesions. MBio, 10, e02785-18. https://doi.org/10.1128/mBio.02785-18

[8] Allen, E.M., Lee, H.Y., Pratt, R., Vang, H., Desai, J.R., Dube, A. and Lightfoot, E. (2018) Facilitators and Barriers of Cervical Cancer Screening and Human Papillomavirus Vaccination among Somali Refugee Women in the United States: A Qualitative Analysis. Journal of Transcultural Nursing, 30, 55-63. https://doi.org/10.1177/1043659618796909

[9] Ali-Risasi, C., Verdonck, K., Padalko, E., Vanden Broeck, D. and Praet, M. (2015) Prevalence and Risk Factors for Cancer of the Uterine Cervix among Women Living in Kinshasa, the Democratic Republic of the Congo: A Cross-Sectional Study. Infectious Agents and Cancer, 10, 20. https://doi.org/10.1186/s13027-015-0015-Z

[10] Hovland, S., Arbyn, M., Lie, A.K., Ryd, W., Borge, B., Berle, E.J., et al. (2010) A Comprehensive Evaluation of the Accuracy of Cervical Pre-Cancer Detection Methods in a High-Risk Area in East Congo. British Journal of Cancer, 102, 957-965. https://doi.org/10.1038/sj.bjc.6605594

[11] Paluku, J.L., Carter, T.E., Lee, M. and Bartels, S.A. (2019) Massive Single Visit Cervical Pre-Cancer and Cancer Screening in Eastern Democratic Republic of Congo. BMC Women's Health, 19, Article No. 43. https://doi.org/10.1186/s12905-019-0737-y

[12] Ali-Risasi, C., Mulumba, P., Verdonck, K., Vanden Broeck, D. and Praet, M. (2014) Knowledge, Attitude and Practice about Cancer of the Uterine Cervix among Women Living in Kinshasa, the Democratic Republic of Congo. BMC Women's Health, 14, 30. https://doi.org/10.1186/1472-6874-14-30

[13] Massad, L., Xie, X., D’Souza, G., Darragh, T.M., Minkoff, H., Wright, R., et al. (2015) Incidence of Cervical Precancers among HIV-Seropositive Women. American Journal of Obstetrics and Gynecology, 212, 606.e1-606.e8. https://doi.org/10.1016/j.ajog.2014.12.003

[14] Blumenthal, P.D., Gaffikin, L., Deganus, S., Lewis, R., Emerson, M. and Adadevoh, S. (2007) Cervical Cancer Prevention: Safety, Acceptability, and Feasibility of a Single-Visit Approach in Accra, Ghana. American Journal of Obstetrics and Gynecology, 196, 407.e1-407.e9. https://doi.org/10.1016/j.ajog.2006.12.031

[15] Söderlund-Strand, A., Eklund, C., Kemetli, L., Grillner, L., Törnberg, S., Dillner, J., et al. (2011) Genotyping of Human Papillomavirus in Triaging of Low-Grade Cervical Cytology. American Journal of Obstetrics and Gynecology, 205, 145.e1-145.e6. https://doi.org/10.1016/j.ajog.2011.03.056

[16] Catarino, R., Vassilakos, P., Tebeu, P.M., Schäfer, S., Bongoe, A. and Petignat, P. (2016) Risk Factors Associated with Human Papillomavirus Prevalence and Cervical Neoplasia among Cameroonian Women. Cancer Epidemiology, 40, 60-66. https://doi.org/10.1016/j.canep.2015.11.008

[17] Yessaian, A., Mendivil, A.A. and Brewster, W.R. (2005) Population Characteristics in Cervical Cancer Trials: Search for External Validity. American Journal of Obstetrics and Gynecology, 192, 407-413. https://doi.org/10.1016/j.ajog.2004.08.027

[18] Benoy, I.H., Vanden Broeck, D., Ruymbeke, M.J., Sahebali, S., Arbyn, M., Bogers, J.J., et al. (2011) Prior Knowledge of HPV Status Improves Detection of CIN2+ by 
Cytology Screening. American Journal of Obstetrics and Gynecology, 205, 569.e1-569.e7. https://doi.org/10.1016/j.ajog.2011.06.101

[19] Lorin, L., Bertaut, A., Hudry, D., Beltjens, F., Roignot, P., Bone-Lepinoy, M.C., et al. (2015) About Invasive Cervical Cancer: A French Population Based Study between 1998 and 2010. European Journal of Obstetrics \& Gynecology and Reproductive Biology, 191, 1-6. https://doi.org/10.1016/j.ejogrb.2015.04.007

[20] Hernádi, Z., Gazdag, L., Szoke, K., Sápy, T., Krasznai, Z.T. and Kónya, J. (2006) Duration of HPV-Associated Risk for High-Grade Cervical Intraepithelial Neoplasia. European Journal of Obstetrics \& Gynecology and Reproductive Biology, 125, 114-119. https://doi.org/10.1016/j.ejogrb.2005.08.005

[21] Sangare, F.B. (2007) Etude Des Facteurs De Risques Des Lesions Dysplasiques Et Cancereuses Du Col De L'Uterus Diagnostiquees. Thèse de Médecine, Université de Bamako, Bamako.

[22] Gordon, J.R., Barve, A., Chaudhari, V., Kosambiya, J.K., Kumar, A. and Gamit, S. (2019) HIV Is Not an Easily Acceptable Disease: The Role of HIV-Related Stigma in Obtaining Cervical Cancer Screening in India. Women's Health, 59, 801-814.

[23] Shin, S.S., Carpenter, C.L., Ekstrand, M.L., Wang, Q., Grover, S., Zetola, N.M., et al. (2019) Cervical Cancer Awareness and Presence of Abnormal Cytology among HIV-Infected Women on Antiretroviral Therapy in Rural Andhra Pradesh, India. International Journal of STD \& AIDS, 30, 586-595. https://doi.org/10.1177/0956462419825950

[24] Mitchell, S.M., Sekikubo, M., Biryabarema, C., Byamugisha, J.J.K., Steinberg, M., Jeronimo, J., et al. (2014) Factors Associated with High-Risk HPV Positivity in a Low-Resource Setting in Sub-Saharan Africa. American Journal of Obstetrics and Gynecology, 210, 81.e1-81.e7. https://doi.org/10.1016/j.ajog.2013.08.038

[25] Husaiyin, S., Han, L., Wang, L., Ma, C., Ainiwaer, Z., Rouzi, N., et al. (2018) Factors Associated with High-Risk HPV Infection and Cervical Cancer Screening Methods among Rural Uyghur Women Aged $>30$ Years in Xinjiang. BMC Cancer, 18, Article No. 1162. https://doi.org/10.1186/s12885-018-5083-1

[26] Tapera, O., Kadzatsa, W., Nyakabau, A.M., Mavhu, W., Dreyer, G., Stray-Pedersen, B., et al. (2019) Sociodemographic Inequities in Cervical Cancer Screening, Treatment and Care amongst Women Aged at Least 25 Years: Evidence from Surveys in Harare, Zimbabwe. BMC Public Health, 19, 1-12.

https://doi.org/10.1186/s12889-019-6749-6

[27] Nega, A.D., Woldetsadik, M.A. and Gelagay, A.A. (2018) Low Uptake of Cervical Cancer Screening among HIV Positive Women in Gondar University Referral Hospital, Northwest Ethiopia: Cross-Sectional Study Design. BMC Women's Health, 18, Article No. 87. https://doi.org/10.1186/s12905-018-0579-Z

[28] Nakalembe, M., Makanga, P., Mubiru, F., Swanson, M., Martin, J. and Huchko, M. (2019) Prevalence, Correlates, and Predictive Value of High-Risk Human Papillomavirus mRNA Detection in a Community-Based Cervical Cancer Screening Program in Western Uganda. Infectious Agents and Cancer, 14, Article No. 14. https://doi.org/10.1186/s13027-019-0230-0

[29] Thay, S., Peprah, S.A., Hur, C., Tramontano, A.C., Goldstein, A.T. and Hong, C. (2019) Prevalence of Cervical Dysplasia in HIV-Positive and HIV-Negative Women at the Sihanouk Hospital Center of HOPE, Phnom Penh, Cambodia. Asian Pacific Journal of Cancer Prevention, 20, 653-659.

[30] Liang, X., Carroll, X., Zhang, W., Wenjing, Z., Liu, G., Li, S., Leeper-Woodford, S., et al. (2018) Socioeconomic and Lifestyle Factors Associated with HPV Infection in 
Pregnant Women: A Matched Case-Control Study in Beijing, China. Reproductive Health, 15, Article No. 200. https://doi.org/10.1186/s12978-018-0645-x

[31] Konate, S. (2006) Dépistage du cancer du col de l'utérus au centre de santé de référence de la commune $\mathrm{V}$ du district de Bamako A propos de 113 cas. Thèse de Médecine, Université de Bamako, Bamako.

[32] Wright, T.C., Stoler, M.H., Behrens, C.M., Apple, R., Derion, T. and Wright, T.L. (2012) The Athena Human Papillomavirus Study: Design, Methods, and Baseline Results. American Journal of Obstetrics and Gynecology, 206, 46.e1-46.e11. https://doi.org/10.1016/j.ajog.2011.07.024

[33] Arora, R., Kumar, A., Prusty, B.K., Kailash, U., Batra, S. and Das, B.C. (2005) Prevalence of High-Risk Human Papillomavirus (HR-HPV) Types 16 and 18 in Healthy Women with Cytologically Negative Pap Smear. European Journal of $O b$ stetrics \& Gynecology and Reproductive Biology, 121, 104-109. https://doi.org/10.1016/j.ejogrb.2004.11.025

[34] Jolly, P.E., Mthethwa-Hleta, S., Padilla, L.A., Pettis, J., Winston, S., Akinyemiju, T.F., et al. (2017) Screening, Prevalence, and Risk Factors for Cervical Lesions among HIV Positive and HIV Negative Women in Swaziland. BMC Public Health, 17, Article No. 218. https://doi.org/10.1186/s12889-017-4120-3

[35] Wudtisan, J., Tantipalakorn, C., Charoenkwan, K., Sreshthaputra, R.A. and Srisomboon, J. (2019) Factors Associated with Development of High-Grade Squamous Intraepithelial Lesions of the Uterine Cervix in Women Younger than 30 Years. Asian Pacific Journal of Cancer Prevention, 20, 1031-1036. https://doi.org/10.31557/APJCP.2019.20.4.1031

[36] Ermel, A., Tonui, P., Titus, M., Tong, Y., Wong, N., Ong'echa, J., et al. (2019) A Cross-Sectional Analysis of Factors Associated with Detection of Oncogenic Human Papillomavirus in Human Immunodeficiency Virus-Infected and Uninfected Kenyan Women. BMC Infectious Diseases, 19, Article No. 352. https://doi.org/10.1186/s12879-019-3982-7

[37] Hooi, D.J., Lissenberg-Witte, B.I., Kenter, G., de Koning, M.N.C., Bravio, I.G., Ardts, K., et al. (2018) Human Papillomavirus (HPV) Prevalence and Associated Risk Factors in Women from Curaçao. PLoS ONE, 13, 25-34. https://doi.org/10.1371/journal.pone.0199624

[38] Coker, A.L., Hopenhayn, C., DeSimone, C.P., Bush, H.M. and Crofford, L. (2009) Violence against Women Raises Risk of Cervical Cancer. Journal of Women's Health, 18, 1179-1185. https://doi.org/10.1089/jwh.2008.1048

[39] Brown, M.J., Thacker, L.R. and Cohen, S.A. (2013) Association between Adverse Childhood Experiences and Diagnosis of Cancer. PLOS ONE, 8, e65524.

https://doi.org/10.1371/journal.pone.0065524

[40] Cadman, L. (2015) Professionals Providing Cervical Screening May Require Training and Support on How to Provide Safe and Sensitive Care for Survivors of Childhood Sexual Abuse. Evidence-Based Nursing, 18, 108. https://doi.org/10.1136/eb-2014-101960

[41] Leite, F.M.C., Amorim, M.H.C., Primo, C.C. and Gigante, D.P. (2016) Violence against Women and Cervical Cancer Screening: A Systematic Review. Journal of Clinical Nursing, 26, 2126-2136. https://doi.org/10.1111/jocn.13328

[42] Godfrey, M.A.L., Nikolopoulos, M., Garner, J.E., Adib, T.R., Mukhopadhyay, D., Rains, J.S., et al. (2018) Conservative Management of Cervical Intraepithelial Neoplasia Grade 2 (CIN2) in Women under 30 Years of Age: A Cohort Study. European Journal of Obstetrics \& Gynecology and Reproductive Biology, 228, 267-273. 
https://doi.org/10.1016/j.ejogrb.2018.07.018

[43] Maree, J.E. and Moitse, K.A. (2014) Exploration of Knowledge of Cervical Cancer and Cervical Cancer Screening amongst HIV-Positive Women. Curationis, 37, 1209. https://doi.org/10.4102/curationis.v37i1.1209

[44] Fitzpatrick, M.B., Dube, M.R.S., Katzenstein, D.A., McCarty, K., Weber, J., Sahoo, M.K., et al. (2019) hrHPV Prevalence and Type Distribution in Rural Zimbabwe: A Community-Based Self-Collection Study Using Near-Point-of-Care GeneXpert HPV Testing. International Journal of Infectious Diseases, 82, 21-29. https://doi.org/10.1016/j.ijid.2019.02.022

[45] Chen, J.Y., Wang, Z.L., Wang, Z.Y. and Yang, X.S. (2018) The Risk Factors of Residual Lesions and Recurrence of the High-Grade Cervical Intraepithelial Lesions (HSIL) Patients with Positive-Margin after Conization. Medicine (United States), 97, e12792. https://doi.org/10.1097/MD.0000000000012792

[46] Fernandez, H. (2005) Traité de gynécologie, Flammarion.

[47] Mukanyangezi, M.F., Sengpiel, V., Manzi, O., Tobin, G., Rulisa, S., Bienvenu, E. and Giglio, D. (2018) Screening for Human Papillomavirus, Cervical Cytological Abnormalities and Associated Risk Factors in HIV-Positive and HIV-Negative Women in Rwanda. HIV Medicine, 19, 152-166. https://doi.org/10.1111/hiv.12564

[48] Stewart Massad, L., Xie, X., Burk, R.D., D’Souza, G., Darragh, T.M., Minkoff, H., et al. (2016) Association of Cervical Precancer with Human Papillomavirus Types Other than 16 among HIV Co-Infected Women. American Journal of Obstetrics and Gynecology, 214, 354.e1-6. https://doi.org/10.1016/j.ajog.2015.09.086

[49] Kadhel, P., Multigner, L., Bardinet, F., Goerger-Sow, M.T. and Janky, E. (2012) Cervical Intraepithelial Neoplasia and Invasive Cancer Risks in Women Infected with HIV in the French West Indies. HIV Medicine, 13, 79-82.

https://doi.org/10.1111/j.1468-1293.2011.00939.x

[50] Garbuglia, A.R., Piselli, P., Lapa, D., Sias, C., Del Nonno, F., Baiocchini, A., et al. (2012) Frequency and Multiplicity of Human Papillomavirus Infection in HIV-1 Positive Women in Italy. Journal of Clinical Virology, 54, 141-146. https://doi.org/10.1016/j.jcv.2012.02.013

[51] de Pokomandy, A., Burchell, A.N., Salters, K., Ding, E., O’Brien, N., Bakombo, D.M., et al. (2019) Cervical Cancer Screening among Women Living with HIV: A Cross-Sectional Study Using the Baseline Questionnaire Data from the Canadian HIV Women's Sexual and Reproductive Health Cohort Study (CHIWOS). CMAJ Open, 7, E217-E226. https://doi.org/10.9778/cmajo.20180151

[52] Agorastos, T., Chatzistamatiou, K., Katsamagkas, T., Koliopoulos, G., Daponte, A., Constantinidis, T. and Constantinidis, T.C. (2015) Primary Screening for Cervical Cancer Based on High-Risk Human Papillomavirus (HPV) Detection and HPV 16 and HPV 18 Genotyping, in Comparison to Cytology. PLoS ONE, 10, e0119755. https://doi.org/10.1371/journal.pone.0119755

[53] Bogani, G., Taverna, F., Lombardo, C., Ditto, A., Martinelli, F., Signorelli, M., et al. (2018) Predicting Factors for High-Grade Cervical Dysplasia in Women with Low-Grade Cervical Cytology and Nonvisible Squamocolumnar Junction. Reproductive Sciences, 26, 44-48. https://doi.org/10.1177/1933719118756747

[54] Wang, J.J., Lyu, L.P., Hu, Q.W., Wan, Z.Q., Dong, J., Pan, M., Shen, W.W. and Zhang, S. (2017) A Proper Triage for Detecting Women with High-Risk Human Papillomavirus Genotypes Other than HPV16/18. European Journal of Obstetrics \& Gynecology and Reproductive Biology, 219, 113-118. https://doi.org/10.1016/j.ejogrb.2017.10.021 
[55] Kasap, B., Yetimalar, H., Keklik, A., Yildiz, A., Cukurova, K. and Soylu, F. (2011) Prevalence and Risk Factors for Human Papillomavirus DNA in Cervical Cytology. European Journal of Obstetrics \& Gynecology and Reproductive Biology, 159, 168-171. https://doi.org/10.1016/j.ejogrb.2011.06.021

[56] Corrêa, C.M., Teixeira, N.C.P., de Araújo, A.C.L., Carvalho, N.O., Castillo, D.M.D., Campos, R.R., et al. (2011) Prevalence and Multiplicity of HPV in HIV Women in Minas Gerais, Brazil. Revista da Associação Médica Brasileira, 57, 418-423. https://doi.org/10.1016/S2255-4823(11)70088-1

[57] Agaba, P.A., Thacher, T.D., Ekwempu, C.C. and Idoko, J.A. (2009) Cervical Dysplasia in Nigerian Women Infected with HIV. International Journal of Gynecology \& Obstetrics, 107, 99-102. https://doi.org/10.1016/j.ijgo.2009.06.006

[58] Takamatsu, R., Nabandith, V., Pholsena, V., Mounthisone, P., Nakasone, K., Ohtake, K. and Yoshimi, N. (2017) Cervical Cytology and Human Papillomavirus among Asymptomatic Healthy Volunteers in Vientiane, Lao PDR. BMC Cancer, 17, Article No. 872. https://doi.org/10.1186/s12885-017-3900-6

[59] Adenis, A., Dufit, V., Douine, M., Ponty, J., Bianco, L., Najioullah, F., et al. (2018) Predictors of Abnormal Cytology among HPV-Infected Women in Remote Territories of French Guiana. BMC Women's Health, 18, Article No. 25.

https://doi.org/10.1186/s12905-017-0493-9

[60] Berraho, M., Amarti-Riffi, A., El-Mzibri, M., Bezad, R., Benjaafar, N., Benideer, A., et al. (2017) HPV and Cofactors for Invasive Cervical Cancer in Morocco: A Multicentre Case-Control Study. BMC Cancer, 17, Article No. 435. https://doi.org/10.1186/s12885-017-3425-Z

[61] Vinodhini, K., Shanmughapriya, S., Sanmugham, S., Senthikumar, G., Das, B.C. and Natarajaseenivasan, K. (2012) Prevalence of High-Risk HPV and Associated Risk Factors in Cases of Cervical Carcinoma in Tamil Nadu, India. International Journal of Gynecology \& Obstetrics, 119, 253-256. https://doi.org/10.1016/j.ijgo.2012.06.019

[62] Vidal, A.C., Murphy, S.K., Hernandez, B.Y., Vasquez, B., Bartlett, J.A., Oneko, O., et al. (2011) Distribution of HPV Genotypes in Cervical Intraepithelial Lesions and Cervical Cancer in Tanzanian Women. Infectious Agents and Cancer, 6, 20. https://doi.org/10.1186/1750-9378-6-20 